DOI: 10.17805/trudy.2017.2.3

\title{
ВЗАИМОСВЯЗЬ ЗАЩИТНО-СОВЛАДАЮЩЕГО ПОВЕДЕНИЯ С ОСОБЕННОСТЯМИ ПСИХОЛОГИЧЕСКОГО ПРОСТРАНСТВА ЛИЧНОСТИ
}

\author{
О. Ю. Олейник \\ ООО «Газпром газнадзор»; Московский гуманитарный университет \\ Н. Е. Коренкова \\ Московский гуманитарный университет
}

\begin{abstract}
Аннотация: В работе изучаются взаимосвязи компонентов защитно-совладающего поведения с особенностями психологического пространства личности. Результаты исследования показывают, что отсутствие четко сформированных психологических границ, снижает суверенность компонентов психологического пространства личности и уменьшает сензитивность к ощущениям вторжения в это пространство, препятствуя своевременному «включению» механизмов психологических защит.

ключевые слова: психологические защиты; совладающее поведение; копингстратегии; психологическое пространство личности; суверенность психологического пространства; психологические границы личности
\end{abstract}

\section{INTERRELATIONSHIP BETWEEN PROTECTIVE AND COPING BEHAVIOUR AND CHARACTERISTICS OF PSYCHOLOGICAL SPACE OF AN INDIVIDUAL}

\author{
O. Y. Oleinik \\ «Gazprom Gaznadzor» Ltd; Moscow University for the Humanities, \\ N. E. Korenkova \\ Moscow University for the Humanities
}

\begin{abstract}
The paper studies interrelations between components of protective and coping behaviour and characteristics of psychological space of an individual. The results show that the absence of clear-cut psychological boundaries reduces the sovereignty of an individual's components of the psychological space and reduces the sensitivity to sensations of invasion into this space, preventing the mechanisms of psychological defenses from «switching-on» timely.

Keywords: psychological defenses; coping behaviour; coping strategies; psychological space of personality; sovereignty of the psychological space; individual psychological boundaries
\end{abstract}

Жизнь в современном российском обществе, по сути, представляет собой череду сменяющих друг друга стрессовых и сложных жизненных ситуаций и определение наиболее оптимальных механизмов, позволяющих преодолеть их, может рассматриваться как важная практическая задача в области индивидуального и группового консультирования. Про- 
цесс адаптации человека к жизненным обстоятельствам и ситуациям является одним из важных регуляторов человеческого поведения. Успешность адаптации человека в значительной мере обеспечивается сформированностью у него механизмов психологической защиты и используемыми стратегиями совладающего поведения. Постоянно усложняющиеся условия современной жизни, неустойчивость и часто непредсказуемость социальных процессов предъявляют все более высокие требования к способности человека преодолевать жизненные трудности. Выработка широкого спектра эффективных способов и стратегий разрешения трудных ситуаций, формирование навыков их гибкого использования адекватных требованиям условий ситуации повышает позитивный потенциал личности, развивает ее психологическую устойчивость.

Переживание человеком уверенности в своей способности преодолевать жизненные трудности способствует развитию чувства компетентности и собственной ценности, повышает самооценку человека, его уверенность в собственных силах, в том, что он может контролировать и созидать свой жизненный мир.

Актуальность данного исследования обусловлена как теоретическими (выяснение роли и места «виртуального» человека в его психологических границах в регуляции поведения в сложных жизненных обстоятельствах), так и практическими (получение информации о возможных направлениях коррекционной работы по формированию жизнеустойчивости молодежи) задачами.

В соответствии с программой исследования было изучено защитносовладающее поведение в контексте его взаимосвязи с особенностями психологического пространства личности.При этом под психологическим пространством личности понималось «субъективно значимый фрагмент бытия, определяющий актуальную деятельность и стратегию жизни человека» (Нартова-Бочавер, 1997, 2004, 2008). В качестве функционального органа психики, обеспечивающего ей условия для взаимодействия с миром, было использовано понятие «психологические границы» (Леви, 2008, 2009).

Гипотезами проведенного нами исследования стали предположения о том, что:

1. Между психологическими защитами и копинг-стратегиями существует взаимосвязь, которая позволит выявить типы защитносовладающего поведения;

2. Между суверенностью компонентов психологического пространства и характеристиками психологических границ существует взаимосвязь, которая позволяет предположить, что обе эти переменные характеризуют особенности психологического пространства; 
3. Типы защитно-совладающего поведения связаны с особенностями психологического пространства личности.

Для решения задач исследования были использованы следующие психодиагностические методики:

- Опросник «Суверенность психологического пространства» С.К.Нартовой-Бочавер. Опросник включает в себя 6 шкал, отражающих измерения психологического пространства: суверенность физического тела, территории, вещей, привычек, социальных связей и ценностей человека;

- «Методика диагностики психологической границы личности» Т.С.Леви. Опросник состоит из шести шкал, соответствующих шести функциям оптимальной психологической границы;

- Методика «Опросник способов совладания» (OCC) Р. Лазаруса и C.Фолкман (WCQ, адаптация T. Крюковой и Е. Куфтяк) предназначена для определения копинг-механизмов, способов преодоления трудностей в различных сферах психической деятельности, копинг-стратегий;

- Опросник «Индекс жизненного стиля» Плутчика-КеллерманаКонте. Методика позволяет диагностировать всю систему МПЗ (механизмы психологической защиты), выявить как ведущие, основные механизмы, так и оценить степень напряженности каждого.

В исследовании приняли участие студенты Академии им. Плеханова. Всего было обследовано 70 человек (50 девушек и 20 юношей).

Результаты. Для обработки полученных данных использовались корреляционный анализ, кластерный анализ, метод кросстабуляционного сравнения и анализ частотного распределения на базе статистического пакета STATISTICA 6.0.

В соответствии с первой гипотезой исследования о том, что между психологическими защитами и копинг-стратегиями существует взаимосвязь, был проведен корреляционный анализ психологических защит с копинг-стратегиями.

Остановимся на описании значимых корреляционных связей, представленных в таблице № 1 .

Таблища 1. Значимые корреляционные связи психологических защит с копинг-стратегиями

\begin{tabular}{|l|r|r|r|}
\hline & \multicolumn{1}{|c|}{ Spearman } & $\mathrm{t}(\mathrm{N}-2)$ & \multicolumn{1}{c|}{-level } \\
\hline Конфронтативный копинг \& Регрессия & 0,243876 & 2,07366 & 0,041901 \\
\hline Конфронтативный копинг \& Компенсация & 0,283219 & 2,43520 & 0,017512 \\
\hline $\begin{array}{l}\text { Конфронтативный к копинг \& } \\
\text { Гиперкомпенсация }\end{array}$ & 0,265761 & 2,27327 & 0,026173 \\
\hline
\end{tabular}




\begin{tabular}{|c|c|c|c|}
\hline Конфронтативный копинг \& ОНЗ & 0,252352 & 2,15055 & 0,035070 \\
\hline $\begin{array}{l}\text { Планирование решения проблемы \& } \\
\text { Рационализация }\end{array}$ & 0,307091 & 2,66091 & 0,009714 \\
\hline Самоконтроль \& Проекция & 0,289383 & 2,49298 & 0,015108 \\
\hline Самоконтроль \& Гиперкомпенсация & 0,285278 & 2,45445 & 0,016675 \\
\hline Самоконтроль \& ОНЗ & 0,299358 & 2,58722 & 0,011818 \\
\hline Положительная переоценка \& Регрессия & 0,280047 & 2,40558 & 0,018872 \\
\hline Положительная переоценка \& Проекция & 0,272891 & 2,33910 & 0,022276 \\
\hline $\begin{array}{lll}\text { Положительная } & \text { переоценка }\end{array}$ & 0,364876 & 3,23164 & 0,001899 \\
\hline $\begin{array}{ll}\text { Положительная } & \text { переоценка } \\
\text { Гиперкомпенсация }\end{array}$ & 0,407684 & 3,68171 & 0,000460 \\
\hline $\begin{array}{lll}\text { Положительная } & \text { переоценка } & \& \\
\text { Рационализация } & & \\
\end{array}$ & 0,289465 & 2,49375 & 0,015077 \\
\hline Положительная переоценка \& OH3 & 0,416179 & 3,77430 & 0,000339 \\
\hline Избегание\& Регрессия & 0,381582 & 3,40418 & 0,001117 \\
\hline Избегание \& Замещение & 0,265118 & 2,26735 & 0,026551 \\
\hline
\end{tabular}

Из данных таблицы видно, что наибольшее число взаимосвязей имеет такая копинг-стратегия, как «Положительная переоценка», которая подразумевает усилия по созданию положительного смысла ситуации, фокусировку на росте собственной личности, включая религиозный опыт. Она взаимосвязана с такими защитами, как регрессия, проекция, компенсация, гиперкомпенсация, рационализация и общая напряженность защит. Из этого следует, что респондентов, часто использующих данную стратегию, характеризует широкий спектр психологических защит. При этом, они отдают предпочтение более конструктивным защитам (у них представлены обе защиты, считающиеся конструктивными - компенсация и рационализация).

Такая копинг-стратегия как «Конфронтативный копинг», которая означает агрессивные усилия субъекта по изменению ситуации, предполагает определенную степень враждебности и готовность к риску, имеет значимые связи с общей напряженностью защит, и с такими защитами, как регрессия, компенсация и гиперкомпенсация. Можно сделать вывод, что чем чаще человек использует данную копинг-стратегию, тем чаще доминирующими в его поведении являются такие защиты, как регрессия, компенсация и гиперкомпенсация. Обратим при этом внимание на то, что среди перечисленных защит нет ни одной деструктивной.

«Планирование решения проблемы», которое включает произвольные, специально предпринятые проблемно-фокусированные усилия по изменению ситуации и аналитический подход к решению проблемы, связана с такой психологической защитой, как рационализацией, суть 
которой состоит в том, что в мышлении используется только та часть воспринимаемой информации, и делаются только те выводы, благодаря которым собственное поведение предстаёт как хорошо контролируемое и не противоречащее объективным обстоятельствам.

Такая копинг-стратегия, как «Самоконтроль», подразумевающая усилия по регулированию своих чувств и действий, связана с общей напряженностью защит и с такими защитами, как проекция и гиперкомпенсация. Из этого можно сделать вывод, что чем выше у человека самоконтроль в трудных ситуациях, тем выше общая напряженность его психологических защит.

«Избегание», под которым понимается мысленное стремление и поведенческие усилия, направленные к бегству от проблемы, связано с регрессией и замещением. Реализация в поведении такой копинг-стратегии как «Избегание» осуществляется с помощью того, что человек бессознательно прибегает к более ранним, менее зрелым и менее адекватным образцам поведения, которые кажутся ему гарантирующими защиту и безопасность.

Далее для выявления типов защитно-совладающего поведения вся выборка при помощи кластерного анализа по средним значениям была разбита на 2 группы, значимо отличающихся между собой по всем перемененным, кроме копинг-стратегии «планирование решения проблем». В первую группу вошло 46 респондентов, во вторую - 24 .

Остановимся на характеристике каждой из выделенных групп. Представители первой группы имеют более высокие средние значения по всем копинг-стратегиям и психологическим защитам, чаще используют такую копинг-стратегию, как «положительная переоценка» и такие виды защит, как проекция и рационализация (таб. № 2).

Исходя из высокой общей напряженности психологических защит назовем данную группу «Группа с высоконапряженным типом защитносовладающего поведения».

Таблица 2. Описательные статистики для первой группы

\begin{tabular}{|l|c|c|c|}
\hline \hline & Среднее & $\begin{array}{c}\text { Стандартное } \\
\text { отклонение }\end{array}$ & Вариативность \\
\hline Конфронтативный копинг & 10 & 2,87485 & 8,2647 \\
\hline Планирование решения проблемы & 13 & 2,75541 & 7,5923 \\
\hline Самоконтроль & 13 & 2,67173 & 7,1382 \\
\hline Положительная переоценка & 13 & 3,65869 & 13,3860 \\
\hline Избегание & 12 & 4,50662 & 20,3097 \\
\hline Регрессия & 37 & 12,66720 & 160,4580 \\
\hline Замещение & 29 & 15,57900 & 242,7053 \\
\hline Проекция & 57 & 17,36207 & 301,4416 \\
\hline
\end{tabular}




\begin{tabular}{|l|c|c|c|}
\hline Компенсация & 50 & 19,99517 & 399,8068 \\
\hline Гиперкомпенсация & 34 & 15,82666 & 250,4831 \\
\hline Рационализация & 54 & 16,86779 & 284,5222 \\
\hline Общая напряженность защит & 39 & 5,96593 & 35,5923 \\
\hline
\end{tabular}

Представители второй группы имеют более низкие средние значения по всем копинг-стратегиям и психологическим защитам. Они чаще используют такую копинг-стратегию, как «Планирование решения проблемы» и такие защитные механизмы, как проекция и рационализация (таб. № 3).

Исходя низкой общей напряженности психологических защит назовем данную группу «группа с низконапряженным типом защитносовладающего поведния».

Обратим внимание, что в типах защитно-совладающего поведения динамичным компонентом является доминирующая копинг-стратегия.

Таблица 3. Описательные статистики для второй группы

\begin{tabular}{|l|c|c|c|}
\hline & Среднее & $\begin{array}{c}\text { Стандартное } \\
\text { отклонение }\end{array}$ & Вариативность \\
\hline Конфронтативный копинг & 8 & 2,68517 & 7,2101 \\
\hline $\begin{array}{l}\text { Планирование решения } \\
\text { проблемы }\end{array}$ & 12 & 3,20750 & 10,2880 \\
\hline Самоконтроль & 11 & 3,58717 & 12,8677 \\
\hline Положительная переоценка & 11 & 2,98517 & 8,9112 \\
\hline Избегание & 9 & 3,66732 & 13,4493 \\
\hline Регрессия & 16 & 9,36140 & 87,6359 \\
\hline Замещение & 12 & 10,49500 & 110,1449 \\
\hline Проекця & 33 & 17,03274 & 290,1141 \\
\hline Компенсация & 14 & 12,09114 & 146,1956 \\
\hline Гиперкомпенсация & 16 & 16,63221 & 276,6304 \\
\hline \hline Рационализация & 33 & 17,15018 & 294,1286 \\
\hline $\begin{array}{l}\text { Общая напряженность } \\
\text { зашит }\end{array}$ & 21 & 8,17372 & 66,8098 \\
\hline
\end{tabular}

Для проверки второй гипотезы исследования о том, что между суверенностью компонентов психологического пространства и характеристиками психологических границ существует взаимосвязь, вся выборка при помощи кластерного анализа по средним значениям была разбита на 2 группы, значимо отличающихся между собой по всем характеристикам психологических границ. В первую группу вошло 36 респондентов, во вторую - 34 .

Остановимся на характеристике выделенных групп.

Представители первой группы находятся в процессе формирования психологических границ (таб. № 4). Они характеризуются большим 
внутренним напряжением, их энергия тратится на поддержание разграничивающих функций границы. Такие люди стремятся сохранить свое пространство, опасаются вторжения, т. е. до конца не вышли из симбиотических отношений. Они закрыты, очень сдержаны в проявлении чувств, копят негативные эмоции, имеют сложности с построением эмоционально-близких отношений, могут чувствовать себя одинокими, не понятыми.

В дальнейшем будем называть эту группу «Группа, находящаяся в процессе формирования психологических границ».

Таблица 4. Описательные статистики для первой группы

\begin{tabular}{|l|c|c|c|}
\hline & Среднее & $\begin{array}{c}\text { Стандартное } \\
\text { отклонение }\end{array}$ & Вариативность \\
\hline Активно не впускающая граница & 17 & 4,551208 & 20,71349 \\
\hline Полностью проницаемая граница & 11 & 3,107594 & 9,65714 \\
\hline Активно вбирающая граница & 12 & 3,008322 & 9,05000 \\
\hline Активно отдающая граница & 14 & 3,820891 & 14,59921 \\
\hline Активно сдерживающая граница & 16 & 3,524405 & 12,42143 \\
\hline \hline Спокойно-нейтральная граница & 13 & 3,868883 & 14,96825 \\
\hline
\end{tabular}

Респонденты второй группы (таб. № 5) - люди с достаточно хорошо сформированными границами: они внутренне спокойны, открыты в своих проявлениях, не склонны удерживать негативные эмоции (но не истеричны). У них полностью сформирована разграничивающая функция границы (процесс выхода из симбиотических отношений завершился), они могут быть в эмоционально-близких отношениях с миром.

В дальнейшем будем называть эту группу «Группа с сформированными психологическими границами».

Таблица 5. Описательные статистики для второй группы

\begin{tabular}{|l|c|c|c|}
\hline & Среднее & $\begin{array}{c}\text { Стандартное } \\
\text { отклонение }\end{array}$ & Вариативность \\
\hline $\begin{array}{l}\text { Активно не впускающая } \\
\text { граница }\end{array}$ & 19 & 3,597013 & 12,93850 \\
\hline $\begin{array}{l}\text { Полностю проницаемая } \\
\text { граница }\end{array}$ & 16 & 2,599877 & 6,75936 \\
\hline $\begin{array}{l}\text { Активно вбирающая } \\
\text { граница }\end{array}$ & 14 & 2,279882 & 5,19786 \\
\hline Активно отдающая граница & 19 & 2,717869 & 7,38681 \\
\hline $\begin{array}{l}\text { Активно сдерживающая } \\
\text { граница }\end{array}$ & 14 & 4,869418 & 23,71123 \\
\hline $\begin{array}{l}\text { Спокойно-нейтральная } \\
\text { граница }\end{array}$ & 16 & 3,515689 & 12,36007 \\
\hline
\end{tabular}


Для проверки второй гипотезы был проведен корреляционный анализ взаимосвязией по характеристикам психологических границ и уровня суверенности компонентов психологического пространства (таб. № 6).

Таблица 6. Взаимосвязи групп по характеристикам психологических границ и уровня суверенности компонентов психологического пространства

\begin{tabular}{|l|c|c|c|}
\hline & Spearman & $\mathbf{t}(\mathbf{N}-2)$ & $\mathbf{p}$-level \\
\hline Группа \& Суверенность физ.тела & $\mathbf{0 , 2 4 1 0 0 3}$ & $\mathbf{2 , 0 4 7 7 1 7}$ & $\mathbf{0 , 0 4 4 4 5 3}$ \\
\hline Группа \& Суверенность территории & $\mathbf{0 , 2 4 7 2 9 0}$ & $\mathbf{2 , 1 0 4 5 7 3}$ & $\mathbf{0 , 0 3 9 0 2 7}$ \\
\hline Группа \& Суверенность личных вещей & $\mathbf{0 , 2 5 9 8 4 4}$ & $\mathbf{2 , 2 1 8 9 4 4}$ & $\mathbf{0 , 0 2 9 8 3 1}$ \\
\hline Группа \& Суверенность привычек & $\mathbf{0 , 2 9 6 5 5 5}$ & $\mathbf{2 , 5 6 0 6 4 8}$ & $\mathbf{0 , 0 1 2 6 7 3}$ \\
\hline Группа \& Суверенность соц. связей & 0,180098 & 1,509810 & 0,135725 \\
\hline Группа \& Суверенность ценностей & 0,169449 & 1,417813 & 0,160812 \\
\hline $\begin{array}{l}\text { Группа \& Суверенность } \\
\text { психологического пространства }\end{array}$ & $\mathbf{0 , 2 9 8 7 4 8}$ & $\mathbf{2 , 5 8 1 4 2 8}$ & $\mathbf{0 , 0 1 2 0 0 0}$ \\
\hline
\end{tabular}

Приведенные данные показывают, что принадлежность к группе по характеристикам психологических границ имеет значимые корреляционные связи с суверенностью тела, территории, личных вещей, привычек и психологического пространства в целом.

Для интерпретации полученных взаимосвязей был использован кросстабуляционный анализ (таб. № 7), позволяющий проанализировать сочетаемость этих двух показателей.

Таблица 7. Сочетаемость принадлежности к группе по характеристикам психологических границ и степени суверенности психологического про-

\begin{tabular}{|l|l|c|c|}
\hline & & 1 группа & 2 группа \\
\hline \multirow{2}{*}{$\begin{array}{l}\text { Суверенность } \\
\text { физического тела }\end{array}$} & Низкие & 9 & 5 \\
\cline { 2 - 4 } & Средние & 23 & 19 \\
\cline { 2 - 4 } & Высокие & 4 & 10 \\
\hline \multirow{2}{*}{$\begin{array}{c}\text { туверенностость } \\
\text { терии }\end{array}$} & Низкие & 9 & 8 \\
\cline { 2 - 4 } & Средние & 22 & 14 \\
\cline { 2 - 4 } & Высокие & 5 & 12 \\
\hline
\end{tabular}




\begin{tabular}{|c|c|c|c|}
\hline \multirow{3}{*}{$\begin{array}{l}\text { Суверенность личных } \\
\text { вещей }\end{array}$} & Низкие & 10 & 5 \\
\hline & Средние & 20 & 21 \\
\hline & Высокие & 6 & 8 \\
\hline \multirow{3}{*}{$\begin{array}{l}\text { Суверенность } \\
\text { привычек }\end{array}$} & Низкие & 10 & 5 \\
\hline & Средние & 24 & 21 \\
\hline & Высокие & 2 & 8 \\
\hline \multirow{3}{*}{$\begin{array}{l}\text { Суверенность } \\
\text { социальных связей }\end{array}$} & Низкие & 7 & 6 \\
\hline & Средние & 13 & 9 \\
\hline & Высокие & 16 & 19 \\
\hline \multirow{3}{*}{$\begin{array}{l}\text { Суверенность } \\
\text { ценностей }\end{array}$} & Низкие & 3 & 6 \\
\hline & Средние & 31 & 24 \\
\hline & Высокие & 2 & 4 \\
\hline \multirow{3}{*}{$\begin{array}{l}\text { Суверенность } \\
\text { психологического } \\
\text { пространства }\end{array}$} & Низкие & 4 & 3 \\
\hline & Средние & 29 & 21 \\
\hline & Высокие & 3 & 10 \\
\hline
\end{tabular}

Представленные данные позволяют сделать вывод, что представители первой группы дали больше низких значений по всем компонентам психологического пространства, кроме ценностей, по сравнению со второй группой. Из этого можно сделать вывод, что у людей, находящихся в процессе формирования психологических границ, суверенность психологического пространства ниже.

Для проверки третьей гипотезы о наличии связи типа защитносовладающего поведения с особенностями психологического пространства был проведен корелляционный анализ этих переменных, не выявивший, однако значимых взаимосвязей.

Тогда, для выявления некоторых тенденций к взаимосвязям, нами был проведен кросстабуляционный анализ (таб. № 8).

Таблица 8. Сочетаемость групп по характеристикам границ и типам защитно-совладающего поведения

\begin{tabular}{|l|c|c|}
\hline & $\begin{array}{c}\text { Группа, находящаяся в } \\
\text { процессе } \\
\text { формирования границ }\end{array}$ & $\begin{array}{c}\text { Группа с хорошо } \\
\text { сформированными } \\
\text { границами }\end{array}$ \\
\hline Высоконапряженный & 22 & 24 \\
\hline тип & 14 & 10 \\
\hline Низконапряженный тип & & \\
\hline
\end{tabular}

Полученные данные показывают, что для большинства респондентов, находящихся в процессе формирования психологических границ, и с низкой суверенностью компонентов психологического пространства 
более характерен низконапряженный тип защитно-совладающего поведения. В то время как, респонденты с хорошо сформированными границами и с высокой суверенностью психологического пространства, используют высоконапряженный тип защитно-совладающего поведения. Из этого можно сделать вывод, что отсутствие четких психологических границ снижает сензитивность к ощущениям вторжения в психологическое пространство и препятствует своевременному «включению» механизмов психологических защит.

Выводы.

1.Междупсихологическимизащитамиикопинг-стратегиямисуществует взаимосвязь, позволяющая выделить два типа защитно-совладающего поведения, а именно высоко- и низконапряженный типы.

2.Отсутствиечетко сформированных психологических границ снижает суверенность компонентов психологического пространства личности и уменьшает сензитивность к ощущениям вторжения в это пространство, препятствуя своевременному «включению» механизмов психологических защит.

\section{СПИСОК ЛИТЕРАТУРЫ}

Леви, Т. С. (2008) Пространственно-телесная модель развития личности // Психологический журнал. № 1. С. 23-33.

Леви, Т. С. (2009) Динамика психологических границ в процессе личностно-развивающей работы, основанной на телесном движении // Культурно-историческая психология. № 1. С. 36-41.

Нартова-Бочавер, С. К. (1997) «Coping behavior» в системе понятий психологии личности // Психологический журнал. № 5, Т. 18. С. 20-30.

Нартова-Бочавер, С. К. (2004) Опросник «Суверенность психологического пространства» - новый метод диагностики личности // Психологический журнал. № 5 (сентябрь-октябрь). С. 77-89.

Нартова-Бочавер, С. К. (2008) Человек суверенный: психологическое исследование субъекта в его бытии. СПб. : Питер. 400 с.

Дата поступления: 15.04.2017.

Олейник Оксана Юрьевна - магистр психологии, аспирант кафедры общей психологии и истории психологии Московского гуманитарного университета; ведущий специалист отдела социального развития Управления по работе с персоналом Администрации ООО «Газпром газнадзор». Адрес: 119415, Россия, г. Москва, пр-т Вернадского, д. 41, стр. 1. Тел.: +7 (495) 701-78-07; +7 (909) 623-01-01. Эл. адрес: wildangel2703@yandex.ru 
Коренкова Наталья Евгеньевна - кандидат психологических наук, доцент, доцент кафедры общей психологии и истории психологии Московского гуманитарного университета. Адрес: 111395, Россия, г.Москва, ул. Юности, д. 5. Тел: +7 (499) 374-67-20; +7 (909) 163-44-73. Эл. адрес: korenkova75@mail.ru

Oleynik Oksana Yurievna, Master of Psychology, Postgraduate Student, DepartmentofGeneralPsychologyandHistoryofPsychology,MoscowUniversity for the Humanities; Leading Expert, Department of Social Development, Human Resources Department, “Gazprom Gaznadzor” Ltd. Postal address: 41, Bldg. 1, Vernadskogo Ave., Moscow, Russian Federation 119415. Tel.: +7 (495) 701-78-07; +7 (909) 623-01-01. E-mail: wildangel2703@yandex.ru

Korenkova Natalia Evgenievna, Candidate of Psychology, Associate Professor, Department of General Psychology and History of Psychology Moscow University for the Humanities. Postal address: 5, Yunosti St., Moscow, Russian Federation 111395. Tel.: +7 (499) 374-67-20; +7 (909) 163-44-73. E-mail:korenkova75@mail.ru

\section{Для циитирования:}

Олейник О. Ю., Коренкова Н. Е. Взаимосвязь защитно-совладающего поведения с особенностями психологического пространства личности [Электронный ресурс] // Научные труды Московского гуманитарного университета. 2017, № 2. URL: http:// journals.mosgu.ru/trudy/article/view/449 (дата обращения: дд.мм.гг.). DOI: 10.17805/ trudy.2017.2.3 